\title{
Comparison of informations from the brownfield catalog and the data needed to evaluate real estate
}

\author{
Zuzana Kramářová ${ }^{1, *}$ \\ ${ }^{1}$ Faculty of Technology, The Institute of Technology and Business, Okružní 517/10, 37001 České \\ Budějovice, Czech Republic
}

\begin{abstract}
At present, the topic of sustainable development of the area with brownfield revitalization is one of the current topics. The revitalization of each brownfield requires a completely individual approach, but the whole process can be generalized into several successive points: the identification and cataloging of the site, the search for the investor and the new suitable functions for the brownfield, the design phase of the project, the authorization processes for the realization of the project, realization of the project, new use of the site and realistic return on investment. One of the major challenges for revitalization is the search for an investor. This is due to many factors, among which the acquisition cost of the property, which is based on units of measurement, excels. The tool used to encourage potential investors can be, for example, databases catalogs of existing brownfields. These contain clearly arranged basic information about individual locations. In view of the easier pricing of the brownfield price (its value), it would be advisable to align this information with the necessary valuation data. The paper therefore deals with comparing the information contained in the brownfield databases and the data needed to determine the brownfield price as a real estate.
\end{abstract}

\section{Introduction to brownfields}

At present, the topic of sustainable development of brownfield revitalization is one of the current topics. In the Czech Republic, this is unfortunately solved unusually and non systematically. It is affected by the current legislation, or rather its absence, in which there is almost no instrument to encourage investors to revive brownfields before building on a green meadow. In the Czech Republic brownfields are not defined or mentioned in any law or decree. The only such tool is the National Brownfields Regeneration Strategy of 2008. Unfortunately, this was not accepted by the Czech government, but only taken into account. [4]. At present, Czech Invest has been preparing a new strategy for several years, which could be submitted to the government again for approval. Without this document, the Czech Republic does not have any background that would clearly state the direction by which the whole issue and its solution should be managed.

\footnotetext{
*Corresponding author: 19511@mail.vstecb.cz
} 
The first prerequisite for stimulating developers is to offer own brownfield sites. This is mainly done using brownfield databases / catalogs. Nor does there exist a single legislative background or methodology to implement these databases. The only legislation underpinned point is the inclusion of brownfields between so-called Recovery and Reclamation Areas, which are phenomenon 4 contained in the Subsidiary for the Analysis of Sustainable Development of the Territory, which is part of the Territorial Analytical Data for Individual Municipalities (hereinafter referred to as the TAD) [4, 7]. With this the area of legislative support in the Czech Republic is exhausted.

Because of the lack of legislative support, there is no uniform definition of brownfield. Since the author has dealt with defining the term several times [4-6] and many different authors with different definitions $[7,8]$, etc., the own definition will be used in following text.

"Brownfield is an unused or ineffective location. This site may consist of a part, one or more buildings or land, or a combination thereof. These properties are interconnected operationally, economically or territorially so that they form a whole. Brownfield or part of it may be contaminated."

The issue of brownfield revitalization is a multidisciplinary field combining many industries - from land-use planning, architecture and construction to environmental industries dealing with remediation of contaminated sites and nature conservation. However, revitalization of each brownfield requires a completely individual approach. This depends not only on the actual condition of the brownfield and its previous uses, but also on the local conditions (transport and technical infrastructure, morphology, limits and regulations in the territory, ...) and current needs and potential of the territory, including the socio-demographic structure in the area. It is just because of the environment that identical approaches to different localities can not be successfully applied.

Despite all the differences, the process of successful revitalization can be generalized into several successive stages - phases. The first one is the identification of the site and its subsequent cataloging, and the process continues with the search of the investor and the selection of a new suitable brownfield function. It is followed by the elaboration of the project documentation for the project completed by the permitting processes for the realization of the project. The next point is the actual implementation of the plan and the last stage is the period of new use of the site and the real appreciation of the return on investments.

One of the major challenges for revitalization is the search for an investor. This is due to many factors, including the acquisition price. In the Czech Republic, this is still less advantageous than investments on green meadow, so called greenfield. At the purchase price of the brownfield, the investor always pays not only the complete state of the buildings, but also the land is classified as building. Most brownfields in the Czech Republic are assessed in terms of the construction and technical condition as 3 (usually on a five-point scale) [5]. This means that significant investments in repairs are necessary. Another factor is the existing layout solution, which may not always meet the current needs and requirements of the current legislation, and therefore building modifications must be made to increase the initial investment. The last item is the price for your own land. This is almost always the price of a building land, which is, despite all efforts to increase the fees for withdrawal from the agricultural land fund from 2015 (Act No. 41/2015 Coll., Amending Act No. 344/1992 Coll. ), still much more than the purchase of loose land, including withdrawal fees. 


\section{Brownfield database}

In order to determine the state of the number and character of brownfields, it is necessary to elaborate their overview in the area. This is most often done in the form of an identification or localization study (hereinafter referred to as an identification study). Their output is usually a clear map of the processed area with a plot of the location of the identified localities, which is supplemented with an information database/catalog on individual localities. It is this catalog that can be used to facilitate the search for an investor, as it serves as a tender list in this case.

In the Czech Republic, as already mentioned above, there is no uniform methodology for the processing of identification studies nor the uniform form or content of brownfield databases. At the same time, there is no obligation for the administrative authorities active in the spatial planning of the brownfield site to record at all, except for the already mentioned phenomenon no. 4 in the UAP [4, 7], but it identifies the sites together with others and does not collect any additional information. Thus, if the identification studies in the territory were processed, they are based entirely on the requirements of the study commissioner and his needs - it is therefore impossible to compare them.

As mentioned above, the database collects specific information about individual locations. In general, the catalog/database is listed by content, followed by a header with summary information on individual municipalities in the area being solved, or the territorial administrative structure of the territory. In addition, the stated scales for individual criteria (for example, assessment of building technical status, designation of site types, type of ownership, etc.) are given in the summary header. Behind the headline is the list of brownfields. These are usually for the sake of clarity in the form of a table, supplemented by map drawings and photo documentation. The vast majority of catalogs are processed in the Czech Republic as one-stage, ie only with basic information slightly extended by some specifics requested by the client. These criteria are roughly 50-60 of the surveyed areas, such as: location, type of site, information on land, rough characteristics of the site as a whole, history of use, information from land-use planning documentation, ownership relations, transport and technical infrastructure, Conservation of nature and other limits, maps, photo documentation $[6,7,9,10]$. On average, there are roughly four items on the information area, which is very low.

From the point of view of the amount of information suited to more detailed site characterization and possible selection, it is now appropriate to process these databases in two stages, ie basic information in the first stage and complementary or expanded in the second stage [6]. This will not lead to too much information being overloaded when you first get acquainted with the sites, but for the other needs in the shortlist, the data from the second level will not be missing.

For these reasons, the comparison of the data contained in the brownfield databases and the information needed for valuation of assets will be based on the recommendation for two-step databases that the author handled in a series of freely related contributions $[5,6,9$, $10]$.

\section{Valuation issues}

In the Czech Republic, many computational mechanisms are used for the pricing of movable and immovable property. The official methods used in legal assessments are laid down in Act No. 151/1997 Coll., On Property Valuation and on Amendments to Certain Acts (Act on Property Valuation) and Decree No. 441/2013 Coll., on Implementation of the Act on the Valuation of Assets (Valuation Decree). Because the pricing approaches are 
many and different, the next text will only be based on the procedures used by the law and the decree.

The law distinguishes three basic types of prices - the usual, extraordinary and detected price. The usual price is simply the sale price of a similar asset, including influences such as location, condition, etc., but without exceptional market circumstances, such as the seller's personal circumstances, natural disasters, etc. This is the value of the thing to be compared. The extraordinary price is, of course, the usual price including extraordinary influences. The price detected is then the price determined by law different from the usual and extraordinary prices [1]. The price detected under the Act on Asset Valuation is determined in several ways: cost, yield or benchmarking way and valuation according to the nominal value, according to the book value or according to the exchange rate or as the agreed price [1].

Furthermore, the law divides property valuation into property valuation (buildings, units, land, permanent crops, property rights to real estate), valuation of property rights, securities, other assets and business establishments. For the purpose of this paper, only the real estate sector, namely land, especially construction and agricultural, land-based buildings, including units in buildings, will be specified. Also, for the purposes of the comparison in the following text, only the price determined according to the valuation decree will be considered, and only the cost method will be considered for the choice of methods.

Interestingly, the Act on Assets Valuation in definitions and breakdown of terms such as construction and land does not rely on the definition of the Building Act and its implementing decrees, but defines them separately. Likewise, the division of buildings and land does not correspond to a common construction or urban structure.

Buildings are classified in the property valuation law as: land, civil engineering and special land, water reservoirs including ponds and other structures. As land developments are further divided into buildings, units and outdoors. Buildings are given the same status as "buildings" which are spatially concentrated and outwardly predominantly enclosed by perimeter walls and roof structures, with one or more bounded utility spaces" [1].

In contrast, the Building Law defines the construction as follows: "Building" shall mean all construction works arising from building or assembly technology, without regard to their construction, construction products, materials and structures, for use and duration ... The building that serves advertising purposes is a building for advertising." [2].

Also the concept of land is solved slightly differently. According to the Valuation Act, the division of land is as follows: "building land, agricultural land registered in the Land Registry (hereafter LR) as arable land, hop fields, vineyards, garden, orchards and permanent grasslands, forest land, which are forest land registered in LR and wooded wooded land, land registered in the LR as water bodies and other land" [1]. Among the building land according to the Act on Assets Valuation belongs: on unbuilt Land listed in the LR as built-up areas and courtyards, areas intended for building according to a valid territorial decision or other corresponding document, areas of the area registered in the LR as gardens or other areas forming a common unit with the building site, areas registered in the LR with building law, According to the LR, built-up land with real buildings not registered in the LR [1].

According to the Building Act, however, the building plot is only a "piece of land, its part or a set of land, defined and intended for the location of a building by a territorial decision or a regulatory plan" [2], ie land with valid permitting documentation, not socalled "Black building". 


\section{Hypothesis and Data Comparison}

The underlying hypothesis is that most of the data needed for real estate valuation is already contained in brownfield databases. The research question then is whether other information can be added to a meaningful extent so that there is no enormous burden on the processor and there is no requirement for a more frequent update rate than the two-year intervals based on the UAP data update.

In order to assess the consistency or difference of the data recorded in the brownfields databases and the information needed for the calculation of the real estate price by the cost method according to the law and valuation of properties, the direct comparative method comparison will best be used. For the sake of clarity, the element needed for valuation will always be taken into account and will be confronted with the data contained in the databases.

According to the valuation decree, there is a different procedure for determining the price of the land and determining the price of the building. However, since brownfields are in the vast majority of objects with land at least under their own ground plan, these criteria will be judged without distinction as to whether the criteria for calculating the price of the land or the building.

Data from brownfield databases (hereinafter referred to as databases) will act as data recommended for or data used in multi-stage databases $[5,6,9,10]$. As their location within the overall database is given the division: data from the total header of the catalog and the data for the individual sites divided into the basic (primary, first degree, basic ...) and extended (additional, secondary, from the secondary stage ...).

According to the Valuation Decree, the price is always determined as the base price adjusted to the unit of measurement, multiplied by the number of units.

\subsection{Comparable data:}

- basic identification data (land number / number, municipality, street and descriptive number, GPS coordinates, ...) - in databases are given in almost identical content between the basic information, usually in the header of the card used to identify the brownfield - area of land - in databases is given in $\mathrm{m} 2$ directly in the basic data, ie the first information step

- length (eg to determine the price for the fencing of the plot) - the data does not appear in the databases; It can be included in secondary information about land or location

- built-up area of the building - in some databases is given in $\mathrm{m} 2$, but not always; it is usually found between secondary information; the data can be included in the databases

- flooring - in databases are usually located in two sources: in the primary information in the description of the site, in the secondary information it is directly enumerated in the description of the individual objects as well as between the information concerning the fire safety of buildings

- floor height - in the databases are reported as the floor height between the extended information on individual objects

- floor height - in the databases are reported as the floor height between the extended information on individual objects

- built-up floor area, floor area - not mentioned in databases, only the total floor area, which is given in some databases for individual objects, in some as the total floor area for all the buildings together, is rather coarse and despite the name rather corresponds built-up floor area than a clean floor area; the data could be partly reconciled with changing the name of the item in the databases, but the precise calculation of the floor areas would be too demanding 
- the building envelope (upper structure, under construction, roofing) - in databases it is usually given between secondary information to individual objects, but is not more closely divided, it is always the sum of $\mathrm{m} 3$ of the building as a whole, eventually only the sum of the enormous space of the superstructure and the roofing; the indication is inappropriate to align, it would be too demanding

- the built-up area of other building objects - in the databases it is given the same as the above mentioned for individual objects

- basic price of the listed municipality - not mentioned in the databases; it is not appropriate to supplement the amendment to the valuation decree, but it is possible to add it to the listed municipalities between the secondary information and the location of the site

- the size of the municipality (by population) - not mentioned in the databases; the data can be added to the overall header of the catalog as it will be the same for several brownfields in the territory and may change over time according to demographic developments

- economical and administrative significance of the municipality - the database is in some cases seemingly included in the characteristics of individual municipalities in the overall heading of the catalog, but its content is completely unresponsive; the harmonization of the content would be misleading due to the focus of studies and databases, since, in terms of valuation decree, it is not a division from a territorial point of view but a characteristic of the economic orientation of the municipality (spa tourism, tourism ...)

- the location of the municipality - in the databases, the data is included in the primary information in the form of a map drawing with a wider environment; however, the content does not correspond to the requirements of the valuation decree, which understands it as distance from economically significant settlements; it could be added to the overall header of the catalog

- technical infrastructure in the municipality - data in databases is not included directly but can be found between primary and secondary information about the brownfield technical infrastructure; data can be added to the overall header of the catalog

- civic amenities of the municipality - data in databases not included; it is appropriate to add it to the overall heading of the catalog, however, the structure required by the valuation decree does not correspond to the existing urbanistic terminology, so it is necessary to consider the content

- inclusion in the city area - not included directly in the database; the data can be added to the listed municipalities

- situation on the sub-property market - data in the database is not included; it is not appropriate to supplement the data because its characteristics require more specialized economic knowledge and knowledge of the current state of the market - the figure may change over time

- ownership relationships - the data are included in the database among the primary information but are fragmented into parts of the site categorization and ownership relations, as in the valuation decree there is also the basic characteristic of the land with the building, unbuilt land, co-ownership, ...; the data is not appropriate to directly harmonize; in the case of the introduction of the data area for the valuation it is possible to supplement it

- changes in the environment with impact on marketability - not included in databases; the information may be added

- the impact of legal relationships on marketability - in databases is implicitly included in the basic information on ownership of the site and the limits

- other non-restrictive effects - in databases is rarely included in the basic information in the notes; the data can be harmonized

- flood risk - the data is indirectly contained in the databases in the primary data between the limits; data can be refined and required in databases 
- the geometric shape of the plot and the size of the plot - the data are indirectly included among the basic information in the area of the size of the plot and the drawing above the cadastral map, which clearly shows the shape of the land; data need not be harmonized

- sloping land and exposure - data in databases not included; they can be added to secondary information about land

- difficult baseline conditions - data in databases are not included; they can be added to secondary information about land

- protected areas and protection zones - in databases is included in the basic data between limits within the territory; it is not necessary to harmonize, it would be at the expense of the accuracy of the other limits described

- type and purpose of the construction - in the databases is contained in the primary information about the current or original use of the site

- the prevailing area surrounding the land and the environment - in the databases is only partially contained in the basic information, this can be read from the brownfield position drawings in the situational map; It is appropriate to supplement the primary information

- the location of the land in the municipality - in the databases indirectly included, can be read from the brownfield position drawing in the situational map; data can be added

- the possibility of linking land to engineering networks - in the databases included in primary and secondary information in the field of technical infrastructure

- civic amenities in the vicinity of the land - data in the databases is not included; it can be added to advanced location data

- transport accessibility to land - in the databases included in primary and secondary information in the field of transport infrastructure

- public transport - in databases included in secondary information in the field of transport infrastructure

- position from the point of view of commercial usability - not in the databases directly; The figure can not be added as it is linked to the use of brownfield, which may change - population in the area - data in databases are not included; they can be added to secondary site information

- unemployment - data in databases are not included; they can be added to the overall header of the catalog

- unlisted effects - not listed in databases; can be included in notes in primary or secondary data

- parking options - listed in secondary information about transport infrastructure

- BPEJ - in the databases listed partly in the primary information when it is I. or II. class of protection; the appropriate addition, depending on the primary or secondary data on land

- categorization of the building type - in the databases partly contained in the primary information about the original purpose of the building; the information can be added between the primary information

- construction and equipment - in the databases included in the secondary information between the assessment of the construction technical condition; there is no need to harmonize

- the type of construction - in the databases included in the primary data in the description of the site as well as in the secondary data in the assessment of the construction technical state; there is no need to harmonize

- structure allowing the use of the attic - data in the databases is not included; it can be added between secondary information in the area of valuation or assessment of the construction and technical condition

- hydromelioration - partially listed in databases, the figure may appear in the primary information in a note or limits (invested agricultural land); it is appropriate to add between secondary information about land 
- age of construction - not included in databases; it is appropriate to add information between the secondary information on the construction technical status or the extended site information

- estimated lifetime - data in databases not listed; it is not appropriate to replenish because it depends on the amount of investment invested in revitalization

The above comparison confirms the basic hypothesis, that in databases are or can be most of the necessary data for real estate valuation reported without the increase of personnel capacities - this is a total of 42 items contained data or data appropriate to supplement or modify / harmonize, making it the total volume of $87.5 \%$. Unsupported and inappropriate for database insertion in any form are 6 items out of a total of 48 , ie $12.5 \%$. Reasons for not including these data in databases are always listed for each type above. This also resulted in answering the research question of possibilities of supplementation missing data into databases.

\section{Concluding}

Comparison of the data recorded in the brownfield databases and the information necessary for the cost method of determining the price of real estate pursuant to Act No. 151/1997 Coll. Shows one of the possible approaches how to generate or verify the utility of the collected data on brownfields. Of course, opinions on the amount of information in the database can vary, and it is possible to discuss the possibilities of inclusion or non-inclusion of the specific information, but the result of the comparison does not affect it fundamentally because most of the data is already included in the sub-blocks of both the primary and secondary levels.

Furthermore, comparison is one of the examples of how these databases can serve practical purposes. The real estate developer will have the vast majority of pre-prepared information, thus shortening the time needed to collect the input data and self-pricing.

And last but not least, this information can be used to improve initial information in the decision-making process of a potential developer when selecting a site for an investment plan - it is always true that more information helps to eliminate later complications that are common in building reconstructions.

\section{References}

1. Law no. 151/1997 Coll., on Property Valuation and on Amendments to Certain Acts (Act on Property Valuation) (Collection of Law, Prague, 1997)

2. Law no. 183/2006 Coll., on Planning and Building Code (Collection of Law, Prague, 2006)

3. Decree No. 441/2013 Coll., on Implementation of the Act on the Valuation of Assets (Valuation Decree) (Collection of Law, Prague, 2013)

4. Z. Kramářová. Procedia Engineering 161, 290-293 (2016)

5. Z. Kramářová. Brownfield?! Proč?! Problém nebo přiležitost, 65 (2014)

6. Z. Kramáŕová. Ecological, functional, urban and architectural problems of brownfields in small towns, 213 (Doctoral thesis, 2006)

7. J. B. Jackson, et al. Metodika inventarizace brownfieldi̊ v úrovni ORP, 32 (2010)

8. V. Jankových Workshop W1-410 Proceedings of workshop, 28-30 (2004)

9. Atelier T-plan, et al. Vyhledávaci studie pro lokalizaci brownfields na území Královéhradeckého kraje (The Main Project, 2006)

10. Atelier T-plan, et al. Vyhledávaci studie pro lokalizaci brownfields na území Jihočeského kraje (The Main Project, 2006) 